the new criminal anthropology as a development of the Lombrosian methods which has shed the defects of that school. On the other hand, a prelimin. ary study of the American criminal by Prof. E. A. Hooton, as reported by Science Service of Washington, more nearly approaches the methods of Lombroso, in that it endeavours to relate delinquency and physical type. Prof. Hooton's conclusions are, however, based on a large number of observations extending over a considerable period. $\mathrm{He}$ is of the opinion that his material justifies the conclusion that criminals in the totality of their physical characters differ from civilians of the same ethnic type. Certain variations of physical type tend to be associated disproportionately with certain types of crime.

\section{Regenerative Braking on Trains}

THE paper on tramway regeneration by $G$. $H$. Fletcher which was read to he Municipal Tramways and Transport Association, the last instalment of a reprint of which appears in the March issue of the Metropolitan-Vickers Gazette, is of great interest to tramway engineers. In regenerative braking, when the electric tram or train is going downhill, its own momentum drives the motors of the car as dynamos, thus absorbing energy and acting like a mechanical brake. It also converts the gravitational potential energy into electrical energy which is restored to the line, helping the power station, and thus leading to economical working. The advantages of the regenerative system are the reduced energy consumption and the reduced wear of brake shoes and wheel tyres, and the consequent lowering of maintenance costs. The disadvantages are that the motors are larger and more costly. There are many examples of remunerative regenerative braking abroad in mountain railways and on lines where the gradients are heavy. The Metropolitan-Vickers Company has equipped two sample tramcars on the Manchester and Glasgow corporation systems respectively with regenerative control. The equipment enables the kinetic energy of the train to be recovered and returned to the line instead of being dissipated in the brakes. The Manchester car has now been on service for some months and the Glasgow car has run several special trials. Both have worked very satisfactorily, effecting appreciable savings in power consumption. A specially equipped car was paired with a standard car and the two worked together for definite periods on a number of routes. The results show that the regenerative tram on an 8.5 miles per hour service on a comparatively flat route took twenty-seven per cent less power than the standard tram.

\section{Annual Symposium on Colloid Chemistry}

THE tenth annual Symposium on Colloid Chemistry will be held in Ottawa, Canada, on June 16-18. About two hundred workers in this field of science are expected to attend the meeting, and Mr. Emil Hatschek, lecturer on colloids at the Sir John Cass Technical Institute in London, will be the principal guest and speaker. He will read a technical paper and will also give an evening lecture; the sessions will be held in the newly constructed National Research Laboratories. Papers will be presented on the colloid chemical aspects of such diverse subjects as: the constitution of rubber, by Thomas Midgley, of Columbus, Ohio; diphtheria toxins and antitoxins, by P. J. Moloney, of the Con. naught Laboratories, Toronto ; asphalts by Charles Mack, of the Imperial Oil Company at Sarnia ; studies in cellulose, by O. Maass, of MeGill University, Montreal ; colloidal arsenic by E. F. Burton, of Toronto University; gelatin, by S. E. Sheppard, of the Eastman Kodak Company, Rochester, N.Y.; resins, by C. $\mathrm{H}$. Winning, of the University of Wisconsin, Madison; cane wax in raw and refined sugar, by C. F. Bardorf, of the St. Lawrence Sugar Refineries, Montreal.

\section{Committee on Slaughter-house Methods and Equipment}

Tre British Science Guild has appointed a Committee on Slaughter-house Methods and Equipment, "To verify and tabulate information relating to methods of, and equipment for, the slaughtering of animals for food, with especial reference to sanitary, dietetic, and humane requirements; to investigate new methods and equipment; to convey information on the subject to local authorities and other bodies and persons ". The Committee consists of Lieut..-Col. Sir Arnold Wilson (chairman), Capt. C. W. Hume (vice-chairman), Mr. John McMath (honorary secretary), and the following members appointed on the recommendation of the bodies indicated: Mr. John Fearn (Institution of Mechanical Engineers); Dr. Charles Porter (Society of Medical Officers of Health); Sir James Douglas and Mr. R. Stephen Ayling (Model Abattoir Society) ; Prof. F. T. G. Hobday and Lieut.Col. T. Dunlop Young (Royal College of Veterinary Surgeons); Mr. J. R. Hayhurst (Royal Sanitary Institute); Lieut.-Col. T. C. R. Moore and Mr. R. O. P. Paddison (Royal Society for the Prevention of Cruelty to Animals). The Medical Research Council has also been invited to recommend a member.

\section{Birds in Inner London}

A sHoRT article in the May number of British Birds (p. 355) reveals unexpected variety of bird life in the heart of a great city. The presence of gulls has become commonplace, and it is not surprising that birds on migration should be heard passing overhead, like the curlews mentioned. But the settling of exhausted landrails and a woodcock, the appearance of young cuckoos in several gardens, of wheatears in Regent's Park, of a black-necked grebe in Kensington Gardens, a cormorant on the cross of St. Paul's Cathedral, and a pair of kestrels nesting in the belfry of St. Paul's School, Hammersmith Road-these are things which must have surprised and delighted the fortunate observers.

\section{Bureau of Contraceptive Advice}

A statistical analysis by Prof. Raymond Pearl on the year's operations of the Bureau for Contraceptive Advice, Baltimore, has been issued. During this, its

No. 3267, VoL. 129] 